\title{
Producción de conocimiento en conflictos socioambientales
}

\author{
Adela Parra-Romero \\ Universidade Estadual de Campinas, Brasil \\ (iD) https://orcid.org/0000-0002-2939-9399 \\ adelaparraromero@gmail.com
}

\section{Introducción}

Los conflictos socioambientales se han configurado como espacios de luchas políticas contra políticas extractivistas en distintos países de Latinoamérica. Casos como Esquel y Famatina en Argentina, el caso Conga en Perú y el caso del páramo de Santurbán en Colombia, son ejemplos de resistencias sociales que han logrado frenar la minería a gran escala (MERLINSKY, 2013; PAREDES PEÑAFIEL; LI, 2019; PARRA-ROMERO; GITAHY, 2017). El escenario en el cual se presentan los conflictos socioambientales envuelve diversos agentes y, en palabras de Bebbignton, involucra además conflictos sobre qué tipo de relación entre sociedad y ambiente debería predominar en un territorio; sobre cómo estos territorios deberían ser gobernados y por quiénes. (BEBBINGTON, 2007, p. 33). 
Este trabajo parte de la idea de los conflictos socioambientales como fuerzas dinamizadoras del cambio social. Un espacio de contradicción creativa donde confluyen mundos en disputa. Son espacios de luchas políticas: por el reconocimiento de las formas de vida de las comunidades, por el derecho a habitar el territorio y por la distribución equitativa de los recursos y los impactos de las intervenciones. Incluso, en muchos casos, el conflicto no se da por la distribución de los recursos sino por la definición misma de qué es lo que está en disputa, por ejemplo, de un lado montañas y del otro, seres tierra. Al respecto, autores como Mario Blaser y Marisol de la Cadena muestran cómo en los conflictos socioambientales con poblaciones indígenas en Canadá o en el Perú, lo que se negocia son los términos mismos de lo que está en conflicto (BLASER, 2013, 2018; DE LA CADENA, 2010, 2015). ${ }^{1}$

Argumento que el conflicto socioambiental configura un espacio donde diferentes experticias y actores se conjugan para producir, difundir y demandar conocimientos, que, junto a otros elementos simbólicos, materiales y estratégicos, constituyen narrativas que coproducen los territorios y las políticas públicas ambientales. En la disputa por la definición, los usos y las relaciones con el medio ambiente y los territorios, diferentes actores producen y demandan conocimientos como resultado, entre otros, del proceso de aprendizaje social que se da en el espacio del conflicto.

En estos espacios se enfrentan diversos actores. Cada uno con una

\footnotetext{
${ }^{1}$ En esta medida la Ontología Política ayuda a superar los problemas que plantean ver este tipo de conflictos como conflictos culturales. Estos últimos distinguen aquellos que tienen creencias de quienes tienen conocimiento. Para Blaser, el problema de estos planteamientos es tratar un conflicto ontológico en términos de un conflicto epistemológico. En el último caso se diría que el conflicto se encuentra entre diferentes perspectivas sobre lo que ya se definió por adelantado que hay: generalmente desde el punto de vista dominante: recursos, animales, no-humanos. Y no, por ejemplo, seres tierra, hermanos ríos, tortugas sociables y con personalidad (BLASER, 2013).
} 
postura sobre el conflicto y sobre la manera de abordarlo. De un lado, se encuentra el Estado quien es el principal ordenador del territorio y quien promulga las políticas públicas en materia de medio ambiente, economía y ordenamiento territorial. También le corresponde al Estado ejercer un control a través de instituciones especializadas sobre la degradación del medio ambiente, la inversión de recursos, la ejecución de obras y el cumplimiento de metas y objetivos tanto de orden nacional como internacional. Se espera, que por lo menos en lo referente a las políticas públicas y al ordenamiento territorial, se cuente con la participación de otros actores importantes como son las instituciones de orden regional, las organizaciones no estatales, las organizaciones civiles y los ciudadanos que directa o indirectamente son afectados por cada medida en particular.

También, se encuentran las empresas y los grupos empresariales que realizan inversiones en proyectos de carácter económico, entre ellos, los proyectos extractivistas. Este tipo de proyectos tienen un carácter sumamente invasivo en el territorio (GUDYNAS, 2014; SVAM$\mathrm{PA}, 2012$, 2019). Al mismo tiempo, son los que realizan grandes inversiones que, de acuerdo con las políticas económicas estatales, producen beneficios al país como el aumento del empleo, la dinamización de la economía y la generación de regalías que permiten retornar estos beneficios a la sociedad. Es decir, parte del camino para alcanzar el crecimiento económico y modernizar diferentes aspectos de la vida nacional pasa por tener inversionistas, proyectos, políticas y una estabilidad jurídica que permita llevar a cabo la industria extractiva, entre otras.

De otro lado, estos proyectos se instalan, en general, en zonas habitadas por campesinos, población afrodescendiente y población indígena. Algunas características para esto son: las grandes extensiones 
de tierra sin urbanizar, la calidad de la tierra, el acceso a fuentes hídricas y, en apariencia, poblaciones deprimidas o con bajos indicadores en términos de calidad de vida. Así, la idea de la modernización, del desarrollo y el aumento de la riqueza en la zona, se convierten en las justificativas para incorporar los proyectos. Por ejemplo, en su texto Producir la naturaleza y hacer el Estado: el ordenamiento territorial en las tierras bajas del Pacífico colombiano (2014), Asher y Ojeda muestran cómo a raíz del cambio en la Constitución Política Colombiana y una nueva biogeopolítica mundial, el Chocó ${ }^{2}$ se convirtió en objeto de nuevas políticas estatales de intervención para conocer su biodiversidad y producir una naturaleza a explotar de una manera diferente a como se explotó por mucho tiempo desde la colonia. (ASHER; OJEDA, 2014).

Desde las comunidades también se ejerce resistencia puesto que se ven en la necesidad de organizarse para defender sus territorios, sus modos de vida y su derecho a tener formas alternativas de desarrollo. En un primer momento se intenta dialogar con las entidades estatales y, de acuerdo con el tipo de intervención, lograr debatir los principios y conceptos en juego. Como lo muestra Asher y Ojeda, respecto del Pacifico colombiano, en los espacios de trabajo se pueden compartir, por ejemplo, los lineamientos que plantean que el Pacífico es biodiverso y, por tanto, la necesidad de conservarlo y protegerlo. El conflicto aparece en quién define el significado de la biodiversidad y de lo que implica conservar. En este ejemplo específico, nos dicen:

\footnotetext{
${ }^{2}$ El Chocó es un departamento de Colombia que concentra una gran Biodiversidad. Es un territorio con población, en su mayoría, afrodescendiente. Tanto el Chocó como la Amazonía colombiana son espacios de conflictos socioambientales. Aspectos como su biodiversidad, la presencia de poblaciones vulnerables protegidas por legislación especial, negociosos ilícitos y una ubicación estratégica tanto para minería, extracción y aprovechamiento de recursos naturales, como para políticas públicas de conservación.
} 
El trabajo de observación participante de Asher en varios encuentros entre los activistas negros y las entidades del Estado mostró que había poco consenso en torno a quiénes iban a determinar lo que constituía la biodiversidad y la manera en que esta iba a ser preservada, especialmente en las tierras afrocolombianas. Mientras los activistas negros hacían énfasis en el valor local o cultural de la biodiversidad, el economista Fernando Casas, director del Proyecto BioPacífico, estaba más preocupado por los elementos científicos y económicos de la diversidad biológica. (ASHER; OJEDA, 2014, p. 160)

Se encuentra un enfrentamiento respecto de los principios y valores que subyacen a la elección de una serie de criterios para conservar, proteger y definir la biodiversidad (o la naturaleza). En el caso de los pueblos afrocolombianos un apelo por la ancestralidad, el conocimiento tradicional y la diversidad cultural se oponen a una visión del Estado basado en la clasificación, estandarización y la eficiencia, entre otros, para producir una naturaleza apta para explotar (ASHER; OJEDA, 2014).

Este ejemplo nos muestra algo que ocurre en otros conflictos: ¿Quién tiene la potestad para definir los criterios sobre los cuáles se toman las decisiones?, ¿Quién tiene el derecho epistémico, es decir, el lugar autorizado de enunciación? Pareciera en primera instancia un enfrentamiento entre diferentes formas de resolver o abordar un asunto específico. Y la política razonable $e^{3}$ nos dirá que se debe privilegiar la forma objetiva y neutral que aprehende la realidad como lo hacen

\footnotetext{
${ }^{3}$ Con política razonable me refiero al concepto acuñado por Mario Blaser sobre la forma en que la política moderna concede una primacía epistemológica a la ciencia basada en dos ideas: 1 . Las diferencias en un conflicto serian diferencias entre perspectivas del mundo y la política seria la forma de encontrar la perspectiva que tenga más factibilidad de hablar de ese mundo real; 2. La ciencia (como sistema) tendría la primacía epistemológica para decidir sobre los criterios de factibilidad basada en la idea de que el conocimiento es una relación entre "un mundo real ahí afuera” y sus “representaciones”. (BLASER, 2013).
} 
las técnicas y la ciencia. Debate saldado. Pero, como ha sucedido en diversos conflictos socioambientales, los movimientos sociales y los activistas han mostrado que: $a$ ) los conocimientos, valores y criterios venidos desde ellos han aportado conceptos y criterios a las políticas públicas y a la ciencia misma (MARTINEZ-ALIER et al., 2014); b) que no siempre se tiene que elegir el sistema que devele la verdad de una situación, sino que la misma situación (qué es la biodiversidad o la conservación) pueden ser coproducidas por diferentes sistemas de conocimiento (JASANOFF, 2004).

Las prácticas de conocimiento o los conocimientos-otros desestabilizan los bordes o fronteras entre los activistas y la academia (conocimiento experto), realizando valiosos aportes a la institución científica (HOSSEINI, 2010; COX, 2014), al establecimiento de políticas públicas (CORBURN, 2005; PORTO; FINAMORE, 2012), a la solución contextualizada de problemas sociales/ambientales (CARROLL, 2015) y al establecimiento de nuevos ordenes sociales (JAMISON, 2006; APARICIO; BLASER, 2008; COY; WOEHRLE; MANEY, 2008). Sin embargo, el conocimiento y su construcción desde lo comunitario y desde el activismo no solo cumple un papel instrumental (qué investigo) sino también una función política, ontológica y ética.

En este sentido, este artículo tiene como objetivo presentar una discusión sobre diferentes modos de producción de conocimiento en conflictos socioambientales (científico, activista y local/comunitario). Me apoyo en la definición amplia de conocimiento propuesta por Polanyi, donde el conocimiento es una forma activa de comprensión de las cosas que se conocen y para lo cual se requiere de habilidades (POLANYI, 1983). En este sentido, el conocer es una acción que requiere de habilidad. En palabras de Morin, el conocimiento es actividad (cognición) y producto de esta actividad (MORIN, 2006, p. 220), 
es creado para algún fin y por lo tanto puede ser específico y relacional (NONAKA; TAKEUCHI, 1999) y adquirido a partir de una reflexión que es hecha sobre la experiencia (HALL et al., 2012). Bajo estas premisas los modos o prácticas de producción de conocimiento que se abordan en este texto enfatizan el carácter material, situado y la naturaleza política del conocer (CASAS-CORTÉS; OSTERWEIL; POWELL, 2008).

El artículo se estructura en una revisión teórica de los modos de producción mencionados, para luego, analizar cómo estos modos se expresan en las prácticas de distintos actores en el marco del conflicto socioambiental. Esta revisión no es una cuestión normativa y espera aportar elementos para la comprensión de cómo emergen en los conflictos distintas redes de producción de conocimiento y que, en este sentido, estos conocimientos también son con las redes que los producen, es decir, los conocimientos que se producen en el contexto de la disputa tienen un carácter situado y político.

\section{Conocimientos y sus formas de producción}

Este apartado presenta diferentes modos de producción de conocimiento, y por tanto diversos conocimientos, que son reportados por la literatura: producción de conocimiento científico, producción de conocimiento local y producción de conocimiento activista resumidos en el Cuadro 1. Estos modos de producción no se encuentran necesariamente aislados o puros, en especial en problemas y situaciones complejas como los temas ambientales. Los presentamos aquí de forma separada como un ejercicio conceptual que permite representar los puntos de partida en que diferentes actores constituyen redes para producir conocimientos. Tampoco se agotan en estos tres modos, 
pues, por ejemplo, no se aborda aquí formas de producción de conocimiento artístico y audiovisual, periodístico, etc.

El modo de producción de conocimiento científico se refiere al tipo de conocimiento que es producido por la institución científica o por profesionales insertos en dichas instituciones como laboratorios, institutos de investigación o universidades (BOSWELL, 2009). El modo de producción local/comunitario se refiere al tipo de conocimiento que es producido por la experiencia y la práctica local de sujetos en interrelación con un ámbito específico como, por ejemplo, el campesino con la tierra, el paciente con su enfermedad, el pescador con el rio, etc. (CORBURN, 2005). Finalmente, con la producción de conocimiento activista aludo al conocimiento que resulta de redes de acción colectiva; redes que componen organizaciones, activistas y sus prácticas que pueden incluir la investigación militante (CARROLL; 2015; CASAS-CORTÉS; OSTERWEIL; POWELL, 2008). 
Cuadro 1. Modos de producción de conocimiento

\begin{tabular}{|c|c|c|c|}
\hline \multirow[b]{2}{*}{ Dimensión } & \multicolumn{3}{|c|}{ Modo } \\
\hline & Científico & Activista & $\begin{array}{l}\text { Local/ } \\
\text { comunitario }\end{array}$ \\
\hline Definición & $\begin{array}{l}\text { Conocimiento } \\
\text { producido en una } \\
\text { red de institución } \\
\text { científica } \\
\text { (profesiones, } \\
\text { laboratorios, } \\
\text { universidades, } \\
\text { agencias de } \\
\text { investigación } \\
\text { estatales, etc.) y } \\
\text { cuyo resultado es } \\
\text { un conocimiento } \\
\text { codificado, } \\
\text { escolarizado y/o } \\
\text { profesional } \\
\text { (BOSWELL, } \\
\text { 2009) }\end{array}$ & $\begin{array}{l}\text { Creación, } \\
\text { articulación, } \\
\text { formulación de } \\
\text { nuevos } \\
\text { pensamientos y } \\
\text { nuevo } \\
\text { conocimiento } \\
\text { que es definido } \\
\text { por el } \\
\text { movimiento } \\
\text { social en sí } \\
\text { mismo, pero en } \\
\text { relación con la } \\
\text { sociedad } \\
\text { (CARROLL, } \\
\text { 2015) }\end{array}$ & $\begin{array}{l}\text { Forma en que } \\
\text { grupos de } \\
\text { personas } \\
\text { detentan un } \\
\text { conocimiento } \\
\text { arraigado en un } \\
\text { lugar geográfico } \\
\text { determinado y en } \\
\text { su relación con } \\
\text { dicho lugar. Es } \\
\text { un conocimiento } \\
\text { que es } \\
\text { constituido por } \\
\text { la experiencia y } \\
\text { la práctica, que } \\
\text { tiene un gran } \\
\text { componente } \\
\text { tácito y que pasa } \\
\text { por procesos de } \\
\text { reflexión y } \\
\text { codificación } \\
\text { como resultado } \\
\text { de procesos de } \\
\text { contestación }\end{array}$ \\
\hline $\begin{array}{l}\text { Función } \\
\text { en las } \\
\text { políticas } \\
\text { públicas }\end{array}$ & $\begin{array}{l}\text { Instrumental } \\
\text { Legitimación } \\
\text { Sustantiva } \\
\text { (BOSWELL, } \\
\text { 2009) }\end{array}$ & $\begin{array}{l}\text { Contrahege- } \\
\text { mónica } \\
\text { Empoderamiento } \\
\text { Prefiguración de } \\
\text { futuros } \\
\text { alternativos }\end{array}$ & $\begin{array}{l}\text { Contrahege- } \\
\text { mónica } \\
\text { Empoderamiento } \\
\text { Defini- } \\
\text { ción/caracte- } \\
\text { rización de sí } \\
\text { mismo }\end{array}$ \\
\hline
\end{tabular}




\begin{tabular}{|l|l|l|l|}
\hline Explicita & $\begin{array}{l}\text { Se moviliza } \\
\text { a partir de } \\
\text { documentos, } \\
\text { tecnologías, } \\
\text { manuales, } \\
\text { profesiones }\end{array}$ & $\begin{array}{l}\text { Se moviliza a } \\
\text { través de } \\
\text { narrativas, } \\
\text { producciones } \\
\text { audiovisuales, } \\
\text { informes, } \\
\text { documentos, } \\
\text { cartas }\end{array}$ & $\begin{array}{l}\text { Se moviliza a } \\
\text { través de la } \\
\text { experiencia } \\
\text { directa (visitas, } \\
\text { recorridos, etc.). } \\
\text { Se codifica } \\
\text { mediante } \\
\text { imágenes, } \\
\text { etnografías y } \\
\text { testimonios }\end{array}$ \\
\hline Tácita & $\begin{array}{l}\text { Imbuido en } \\
\text { las } \\
\text { habilidades } \\
\text { del } \\
\text { investigador } \\
\text { y en las } \\
\text { prácticas de } \\
\text { los lugares } \\
\text { de } \\
\text { producción }\end{array}$ & $\begin{array}{l}\text { Imbuido en las } \\
\text { prácticas de } \\
\text { organizaciones y } \\
\text { grupos que } \\
\text { componen el } \\
\text { movimiento } \\
\text { social. Imbuido en } \\
\text { las prácticas del } \\
\text { activista }\end{array}$ & $\begin{array}{l}\text { Imbuido en las } \\
\text { practicas del } \\
\text { individuo con su } \\
\text { entorno, lugar o } \\
\text { situación }\end{array}$ \\
\hline
\end{tabular}

Fuente: Elaboración propia con base en las fuentes citadas al interior del cuadro.

Estos modos de producción pueden, en algunos contextos y momentos específicos, colaborar, complementarse y coproducirse. Incluso, la misma investigación militante es la muestra de una producción científica comprometida que puede ser contrahegemónica. O, por ejemplo, movimientos sociales y poblaciones locales pueden producir conocimiento científico como los movimientos en la lucha contra el VIH o el cáncer de mama y poblaciones locales constituyendo sus propios métodos de recolección y procesamiento de información para demostrar científicamente niveles de contaminación en sus territorios o en sus cuerpos. ${ }^{4}$ No hablo de la ciencia como un bloque aislado o de

\footnotetext{
${ }^{4}$ Este tipo de producción de conocimiento se incrementó a partir de la década de 1980 por el trabajo de las asociaciones de pacientes de enfermedades como el cán-
} 
los movimientos sociales como grupos al margen. A lo que me refiero es que los modos constituyen redes que pueden usar elementos en común (formas científicas, conocimiento local etc.) pero que se diferencian en cómo cada modo constituye una red de productores, cierto tipo de actores principales liderando los procesos, formas específicas de validación de resultados, así como ciertas maneras de movilizar de forma explícita y tácita los conocimientos y con ciertos valores políticos y formas de ver/producir lo estudiado.

Si bien los estudios sociales de la ciencia y la tecnología muestran la estrecha relación entre ciencia y política, nos dirá Latour (1994) que la ciencia moderna nos muestra éstas como dos esferas independientes, muchas veces sustentada bajo los preceptos de objetividad y no-neutralidad de la ciencia. Sin embargo, el conocimiento producido y movilizado por los movimientos sociales es claramente enunciado como un conocimiento situado y no-neutral. ${ }^{5}$ Con unas implicaciones políticas, éticas y ontológicas que, si bien como dice Boaventura Santos (2010) no escapa de una pretensión de objetividad ni de una jerarquía de saberes y mucho menos de un diálogo con la ciencia, si tiene como objetivo subvertir las estructuras de poder/conocimiento hegemónicas para lograr cambios sociales de acuerdo con sus demandas.

cer y como respuesta de comunidades y movimientos sociales a problemas como la biopiratería, la contaminación y la injusticia ambiental. En el caso de las comunidades indígenas el paso hacia estados más interculturales llevó a que dichos sistemas de conocimiento fueran reconocidos e incorporados en la gestión de políticas y territorios en países como Canadá (LAVE, 2012, p. 26).

${ }^{5}$ Gran parte de los conocimientos producidos y movilizados en los movimientos sociales tienen una pretensión de ser objetivos, verificables y reproducibles. Es el caso de la epidemiologia popular, aunque situados en el contexto en que son producidos los datos, permiten aportar evidencia empírica para el desarrollo de políticas y programas en el tema de la salud pública (CORBURN, 2002, 2003, 2005, 2007; PORTO; FINAMORE, 2012). 


\section{Modo científico de producción de conocimiento}

El trabajo de Gibbons y colaboradores reconoció dentro de la producción de conocimiento científico, dos modos de producción al que denominaron modo 1 y modo 2 (GIBBONS et al., 1994). En el modo 1 se ubica una forma de producir conocimiento de manera disciplinar, que impulsa a la ciencia basado en los intereses científicos de avance del conocimiento en una disciplina específica, como la física y la matemática (OSORIO, 2005). En este modo de conocimiento la ciencia es considerada como un saber metódico que versa acerca de verdades generales; también es considerada como una operación intelectual acerca de leyes de la naturaleza, basada en datos observacionales y respaldada mediante el experimento (OSORIO, 2005, p. 6). En el modelo tradicional de producción de conocimiento (modo 1), los beneficios de la ciencia pasan a la sociedad mediante la movilización y aplicación que se deriva de la tecnología (ciencia aplicada) y el público usa este conocimiento sin necesitar entenderlo.

En el modo 2 ya no es suficiente un interés científico y una revisión y validación de los pares, sino que debe incluirse la generación de conocimiento dentro de un contexto de aplicación, una mayor responsabilidad social y un control de calidad que ya no está determinado solo por la calidad científica, sino que incluye criterios más amplios (GIBBONS et al., 1994, p. 99). Así, el modo 2 trabaja de manera interdisciplinar y con un enfoque en la resolución de problemas. Se caracteriza por una mayor flexibilidad en los equipos de trabajo que se organizan en redes, suelen ser heterogéneos, trabajan en contextos de problemas y amplían los lugares de la producción de conocimiento (OSORIO, 2005) a la vez que se somete a presiones de responsabilidad por parte de la opinión pública. Lo que se puede considerar como 
un cambio en la forma de producción de conocimiento científico que nace del cambio en la sociedad, sus normativas y las demandas de conocimiento que plantean (PESTRE, 2003). ${ }^{6}$

Un modo no implica que reemplaza al otro, sino que ellos coexisten operando simultáneamente en diferentes contextos. Se podría decir que los modos de producción se corresponden con lo que la ciencia posnormal caracteriza como los dos tipos de sistemas u objetosproblemas: el sistema simple (lo que no implica que no incluya diversos tipos de dificultad) que es estudiado por las ciencias disciplinares -generalmente las ciencias exactas - y los sistemas complejos estudiados por ramas como la ecología y las ciencias humanas. En palabras de Porto, la diferencia entre ambos sistemas es la imposibilidad del segundo de poder ser estudiado desde una sola perspectiva (PORTO, 2012). Al respecto, plantea el autor que entre más complejo es el sistema sobre el cual se desea producir conocimiento, mayor será la importancia de la dimensión cualitativa. En relación con el campo ambiental, y después de trabajar en su libro sobre el modo 2, Gibbons y colaboradores muestran que el modo de producción científica se transforma en relación con el cambio social. Al respecto, el campo ambiental es un ejemplo de los cambios que experimentó el modo de producción científico: nuevas alianzas entre disciplinas como la economía y la ecología, la influencia de las ONG’s que vincularon el conocimiento científico con el conocimiento local y la influencia de los movimientos sociales para redefinir la agenda ambiental (NOWOTNY; SCOTT; GIBBONS, 2001).

Existiría un modo 3 que Callon llama coproducción y que se dife-

\footnotetext{
${ }^{6}$ Otras disciplinas como la economía del conocimiento y la economía de la innovación han trabajado modelos más complejos de la producción y transferencia del conocimiento para áreas del mercado y la gestión de la innovación. (ZUKERFELD, 2018).
} 
rencia de los modos anteriores de la siguiente manera:

En el Modelo 1, la prioridad es la educación de un público científicamente analfabeto. En el Modelo 2, el derecho a la discusión es lo primero porque los legos tienen conocimientos y competencias que mejoran y completan los de los científicos y especialistas. Sin embargo, más allá de sus diferencias, estos dos modelos comparten una obsesión común: la de la demarcación. El Modelo 1, de manera contundente, y el Modelo 2, de una manera más suave y pragmática, niegan a los legos cualquier competencia para participar en la producción del único conocimiento que vale: el que garantiza el término "científico". En el Modelo 1 la exclusión es total; en el Modelo 2 se negocia, pero en ambos casos, el temor es que los laboratorios sean asaltados por hordas de no especialistas. La coproducción del modelo de conocimiento, Modelo 3, tiende a superar estos límites al involucrar activamente a los legos en la creación de conocimiento que los concierne. (CALLON, 1999, p. 89).

En el Modo 3, propuesto por Callon, el conocimiento científico es el resultado de la tensión permanente entre especialistas y no especialistas. Es decir, la constante tensión entre la producción de conocimiento estandarizado y universal, por un lado, y la producción de conocimiento que toma en cuenta la complejidad de las situaciones locales singulares (CALLON, 1999, p. 89). Al respecto, Callon y Rabeharisoa muestran los diferentes tipos de relaciones que se presentan entre pacientes con distrofia muscular y los médicos-investigadores. Estas relaciones entre científicos y no científicos plantean que no existe una división claramente definida entre lo que el autor denomina conocimiento experto y conocimiento lego. Sugiere una coproducción que emerge de la relación entre científicos y grupos de usuarios. Estas relaciones pueden ser de cooperación, de complementariedad o de conflicto. A su vez, cada relación tiene sus efectos no sólo en el conocimiento construido, sino en los mismos actores que permanentemente están redefiniéndose y posicionándose dentro de aquellas relaciones. 
Sin embargo, el conocimiento resultante, al estar predominantemente constituido por los elementos de una red de instituciones, personas y redes científicas, es constituido como conocimiento científico (CALLON; RABEHARISOA, 2003).

En este sentido, el conocimiento científico se produce de forma disciplinar (modo 1) y de manera interdisciplinar (modo 2) y es resultado no solo de los principios científicos de sistematización, objetividad, reproducibilidad y validez, sino que su producción es también el resultado de las relaciones entre laboratorios de investigación, universidades, redes de financiación (ya sea estatal o privada), sistemas de construcción de autoridad científica, ${ }^{7}$ presiones de la sociedad, el Estado y las fuerzas del mercado (LAVE, 2012). Por otro lado, en términos de las políticas públicas y su relación con el conocimiento científico, Christina Boswell (2009) plantea que, aunque se delegue a agencias estatales de investigación para hacer investigación que alimente la política (policy), muchas veces este conocimiento, que es producido específicamente para la política, no es usado por los policymakers, lo que no disminuye su continuo interés por la investigación. La tesis de la autora es que el conocimiento científico tiene un gran valor para los policymakers y juega un papel crucial en la política pública que se basa en sus funciones simbólicas. ${ }^{8}$

\footnotetext{
${ }^{7}$ Para Polanyi una de las cuestiones o los papeles que cumple el conocimiento tácito es la constitución de lo que denomina la autoridad científica. A partir de la creencia de que la ciencia es una colección de objetos o hechos verificables, plantea que realmente no es fácil para un lego o para un científico de otra área verificar cada hecho presentado por la ciencia. Y que, entonces, la credibilidad de la ciencia viene en gran parte de la autoridad que tiene un científico sobre sus hallazgos. Dicha autoridad proviene o es "impuesta" como resultado del control que ejercen los científicos (boundary work) de los canales sobre los cuales los científicos someten sus contribuciones a otros científicos. (POLANYI, 2010).

${ }^{8}$ Función de legitimación a través de la autoridad epistémica, función sustantiva, donde el conocimiento científico es usado, no para legitimar organizaciones o sus miembros y sí para proveer de autoridad a ciertas posiciones políticas, es un uso fre-
} 


\section{Modo activista de producción de conocimiento}

La producción de conocimiento asociado a los movimientos socia$\operatorname{les}^{9}$ impacta diversas esferas sociales y políticas. En la Ecología Política, Martínez-Alier estudia la producción de conocimiento en los movimientos sociales de justicia ambiental desde las relaciones entre las teorías académicas, tales como la economía ecológica y la ecología política, y la práctica activista de las organizaciones sociales de justicia ambiental (MARTÍNEZ-ALIER et al., 2011). Las organizaciones sociales y sus redes mejoran sus capacidades a través del uso y la incorporación de conceptos acuñados en el ámbito académico; pero también estas redes desarrollan nuevos conceptos que se vuelven objeto del escrutinio académico y en algunos casos llegan al discurso de las políticas públicas (JAMISON, 1998; HESS et al., 2008; MARTÍNEZ-ALIER et al., 2011). En un trabajo similar, Cox propone que la sociología puede inspirarse en las prácticas cognitivas de los

cuente en arenas políticas altamente controversiales, puesto que ayuda a devaluar la posición de agencias u organizaciones rivales; y finalmente, la función instrumental, por la cual el conocimiento producido por la investigación científica ayuda a resolver problemas y por tanto mejora la calidad de los resultados en términos de la política pública (BOSWELL, 2009).

${ }^{9}$ Existen tantas definiciones como teorías para explicar los movimientos sociales, he elegido aquí traer los elementos de tres autores para resaltar los elementos heterogéneos que se ponen en juego para componer esta red de producción de conocimiento. En su análisis de las teóricas clásicas sobre los movimientos sociales Gohn (2006) resalta que los movimientos son manifestaciones de descontento en la cohesión social y que ese descontento puede ser caracterizado por el tipo de objetivos de cambio social al que aspiran. En esta vía, nos dice Mendiola (2002) que los movimientos sociales son entramados relacionales que se aglutinan alrededor de una identidad (objetivo y conjunto de valores y normas entorno a un fenómeno/problema) para incidir en el cambio social y que sus acciones no son esporádicas. Finalmente, Parra y Gitahy (2017) nos dicen que los movimientos sociales, como una red compleja, involucran diferentes materiales de la naturaleza, prácticas culturales, modos de relacionarse con el territorio y las prácticas nuevas o las estrategias que surgen de la asociación de diferentes actores para la atención de sus demandas. 
movimientos sociales, quienes, desde su espacio organizativo, sus procesos de producción de conocimiento y de educación popular pueden ayudar a renovar el proceso teórico, de enseñanza y de investigación de la disciplina (COX, 2014).

Los movimientos sociales son sitios importantes en la producción de conocimientos, así como en su reformulación y difusión. La conceptualización de conocimiento va más allá de los modos tradicionales de conocimiento científico. Así, ciertos autores conceptualizan las prácticas de conocimiento no solo en las expresiones del conocimiento científico o experticia en política pública y en política, sino también en la micropolítica y las intervenciones culturales que se relacionan más con el saber cómo o con la praxis cognitiva que tiene toda actividad social (CASAS-CORTÉS; OSTERWEIL; POWELL, 2008; CASAS-CORTÉS, 2009; OSTERWEIL; ESCOBAR, 2010). Entender la producción de conocimiento desde los movimientos sociales ayuda a comprender los efectos políticos de la acción colectiva. Estos conocimientos toman forma en historias, ideas y narrativas; pero también en teorías, experticias, análisis político y conceptualizaciones críticas de contextos particulares (CASAS-CORTÉS, 2009). Visibilizan lo que otros intentan invisibilizar (racismo, abusos, contaminación) y en ese sentido los movimientos sociales producen nuevas formas de ver el mundo (más igualitario, ecológico, feminista), en este sentido, el conocimiento construido es sobre el mundo y desde abajo (COX; FOMINAYA, 2009). ${ }^{10}$

\footnotetext{
${ }^{10}$ Mientras que en el modo de producción académico la principal forma de validación del conocimiento son las redes de revistas indexadas, libros, congresos académicos y ciertos indicadores de producción científica, que en su conjunto proveen lo que Polanyi llamó autoridad científica; en el modo de producción activista, que incluye el conocimiento militante, interesa más la revisión y reflexión constante en y con las organizaciones comunitarias y activistas. El conocimiento se pone a prueba constantemente y se circula por canales de divulgación más amplios como redes
} 
¿Cómo los movimientos sociales producen conocimiento? Al respecto, Cox y Fominaya plantean que se ha intentado responder a esta pregunta desde dos perspectivas. En la primera, se analiza el conocimiento subalterno en contra del conocimiento oficial: lo que conoce el esclavo, la mujer, el colonizado, el trabajador, el oprimido, etc., que está oculto o negado por el maestro, el hombre, el colono, el empleador o el opresor (COX; FOMINAYA, 2009, p. 4). Desde de esta perspectiva, los movimientos sociales están (1) comprometidos con coproducir, desafiar y transformar los discursos de experticia científica. (2) creando "temas críticos" cuyos discursos producen nuevas nociones de democracia. (3) crean teorías reflexivas, coyunturales, contra aproximaciones más dogmáticas y ortodoxas del cambio social y por tanto contribuyen a formas más éticas del conocer (CASAS-CORTÉS; OSTERWEIL; POWELL, 2008; CASAS-CORTÉS, 2009). La segunda perspectiva estudia los procesos específicos de producción de conocimiento que están ligados al desarrollo del movimiento social: cómo los movimientos generan análisis, estrategias y tácticas para producir y movilizar contenidos, reflexiones y entendimientos de la práctica interna, etc. (COX; FOMINAYA, 2009). Sin embargo, ambas perspectivas son inseparables de un análisis sobre la producción de conocimiento activista.

Por otro lado, Jamison estudia las olas de cambio tecnológico y las fases de los movimientos sociales para mostrar la relación e interacción entre ciencia, tecnología y los movimientos sociales (JAMISON, 2006). No es coincidencia que los períodos entre el final de una ola

de justicia ambiental, medios de comunicación, foros de divulgación y en estrados judiciales, entre otros. No significa que en algún momento este conocimiento no termine circulando por revistas y eventos académicos. Sino que el conocimiento que se produce en el modo activista tiene un cierto carácter político de urgencia, como por ejemplo proveer evidencia empírica en las altas cortes legislativas. 
de cambio y otra (marcada por la recesión y el estancamiento económico) también se caracterizaron por una intensa actividad cultural y de protesta social. Al responder a una ola de industrialización, los movimientos sociales han ayudado a construir la siguiente. En cada ola hubo procesos característicos de apropiación cultural de la praxis cognitiva de los movimientos que gradualmente se fueron transformando en discursos científicos, instituciones y prácticas sociales. La praxis cognitiva haría referencia no solo al contenido de la producción del conocimiento sino también al carácter práctico, experiencial y situado que se obtiene en el hacer (JAMISON, 2001). Como se muestra en la Figura 1, la praxis cognitiva de los movimientos sociales se relaciona con procesos también de aprendizaje dentro del movimiento y puede surgir (no exclusivamente) de la integración de lo que Jamison denomina niveles de demandas de conocimiento (cosmológico, organizacional y tecnológico) (JAMISON, 2006) y con los momentos educacionales de O’Sullivan (critica, resistencia y creación) (O’SULLIVAN, 1999 apud COX, 2014).

En el momento de crítica, se controvierte los lugares de producción de conocimiento, las instituciones sociales y las categorías sociales dominantes. En este momento las instituciones, ordenes sociales, estudios específicos e instrumentos de política se convierten en los sujetos de contestación. Esta crítica viene acompañada de una visión/idea de cómo deberían ser (o no ser) - cambiar los métodos, los contenidos de informes, las instituciones o los impactos políticos de la ciencia y políticas públicas - lo que denomina Jamison la dimensión cosmológica de los movimientos sociales. (JAMISON, 1998). En el proceso de resistencia es cuando los movimientos sociales despliegan sus tácticas y estrategias colaborativas para aumentar la participación en diferentes espacios políticos: tomar medidas disruptivas como la 
protesta pública, desafío estatal, la producción de contra narrativas, entablar procesos jurídicos, producir contra-informes y/o hacer la movilización de conocimientos activistas. Para Cox (2014), desde la sociología este momento se convierte crucial para explorar áreas como la democracia, la participación y otras formas de organización y cultura popular. La dimensión tecnológica o momento de creación, se refiere a los principios sobre nuevas formas de coproducir los problemas sociales, aportando para ello principios tecnológicos otros, nuevos métodos, diálogos entre diversos sistemas de conocimiento, tecnologías alternativas o instituciones de orden ciudadano/popular (JAMISON, 2006; COX, 2014).

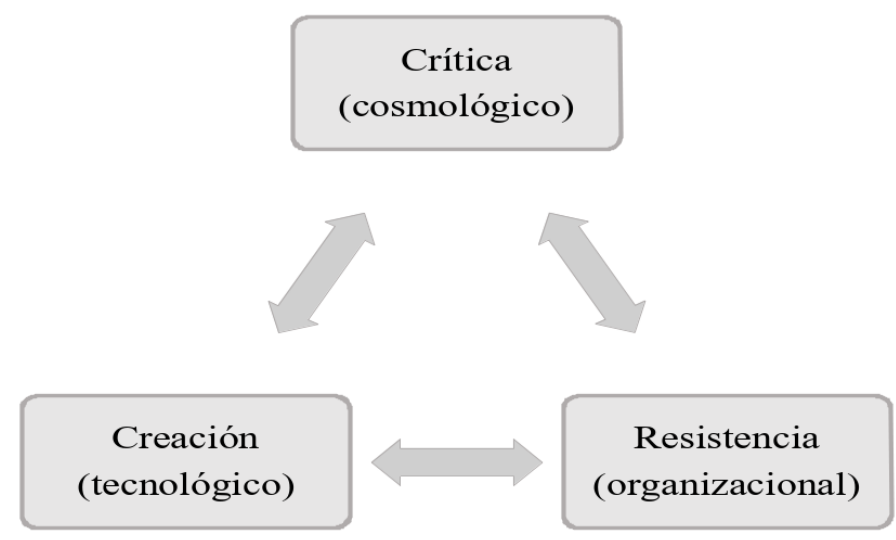

Figura 1. Proceso de producción y movilización de conocimiento en movimientos sociales

Fuente: elaboración propia, basada en Jamison $(1998,2006)$ y Cox (2014).

Como se muestra en el Cuadro 2, los movimientos sociales deben producir, discutir y movilizar conocimientos, a la vez que como movimiento social debe encontrar los canales, las alianzas y las redes para que dicho conocimiento logre desafiar las instituciones, leyes, políticas y lugares hegemónicos. Todas estas características apuntan 
a que el movimiento produzca conocimiento (qué conocer) contrahegemónico. Pero su éxito (que logre desafiar, controvertir y cambiar la hegemonía) depende también de otros factores referentes a la constitución del movimiento y sus estrategias (métodos, redes, difusión) y a la respuesta de los actores e instituciones (reglas para la participación, control de las empresas) (MCCORMICK, 2009).

Cuadro 2. Características para la producción y movilización de conocimiento contrahegemónico en los movimientos sociales

\begin{tabular}{|l|l|}
\hline Características & Funciones \\
\hline $\begin{array}{l}\text { Sujeto de } \\
\text { contestación }\end{array}$ & $\begin{array}{l}\text { Estudios específicos, institución científica, } \\
\text { paradigmas o métodos científicos, conceptos y } \\
\text { categorías movilizadas institucionalmente }\end{array}$ \\
\hline Meta & $\begin{array}{l}\text { Cambiar los métodos, contenidos, instituciones o los } \\
\text { impactos políticos de la ciencia y políticas públicas. } \\
\text { Discutir públicamente categorías sociales. } \\
\text { Reconceptualización de categorías sociales }\end{array}$ \\
\hline Tácticas & $\begin{array}{l}\text { Participación, protesta pública, desafío estatal, } \\
\text { organización, movilizaciones, contra narrativas, } \\
\text { procesos jurídicos, producción de contra-informes, } \\
\text { movilización de conocimientos activistas }\end{array}$ \\
\hline $\begin{array}{l}\text { Estructura } \\
\text { Colaborativa }\end{array}$ & $\begin{array}{l}\text { Activistas/científicos, otros movimientos sociales, } \\
\text { medios de comunicación, activistas/abogados }\end{array}$ \\
\hline $\begin{array}{l}\text { Motivación para } \\
\text { la producción de } \\
\text { conocimiento }\end{array}$ & $\begin{array}{l}\text { Control corporativo de la ciencia, falta de } \\
\text { participación en la toma de decisiones políticas, } \\
\text { injusticia epistémica, injusticia social y ambiental }\end{array}$ \\
\hline
\end{tabular}

Fuente: elaboración propia, basado en Mccormick (2007, 2009),

Choudry (2014) y Conde (2014).

\section{Modo local/comunitario de producción de conocimiento}

El conocimiento local se relaciona con la información perteneciente a contextos locales y sus características, así como el conocimiento 
sobre circunstancias específicas, eventos y relaciones y la comprensión de los significados de dichos conocimientos (CORBURN, 2005). Para Corburn, los científicos y otros profesionales tienden a asumir que las personas tienen poco conocimiento y que poco pueden aportar en términos de análisis complejos excepto sus percepciones y valores. ${ }^{11}$ En este mismo texto, nos habla Corburn sobre que el conocimiento local implica una práctica de cómo es producido el conocimiento. Esto es, que las personas adquieren dicho conocimiento a través de la experiencia más allá de ser un cuerpo estático de información esperando para ser adquirido en un lugar determinado. El autor selecciona el término "conocimiento local” para llamar la atención sobre el carácter basado en el lugar de este tipo de conocimiento. Son conocimientos específicos que las personas o comunidades tienen sobre su cotidiano y su lugar, tanto de las expresiones materiales (clima, suelo, ríos, sus características y ciclos) como de los aspectos socioculturales (normas sociales, formas de organización social etc.). (TADDEI, 2015).

Los conocimientos generados por los actores comunitarios y/o locales son importantes porque son "naturalezas" basadas en el lugar (ESCOBAR, 1998, 2000), geográficamente específicos y basados en la relación que los pueblos tienen con el mismo (BRIGGS, 2013). Existe en ellos, la necesidad de construir maneras autónomas de pensar, ser y hacer; y esto, más que un proceso de identidad corresponde

\footnotetext{
${ }^{11}$ Esto no quiere decir que no haya excepciones. Las escuelas críticas de la poscolonialidad (BHAMBRA, 2014) y la Decolonialidad han hecho un esfuerzo por descolonizar la ciencia y reconocer los saberes otros (CASTRO-GÓMEZ; GROSFOGUEL, 2007). Ciencias como la agroecología han tenido sus raíces en los saberes campesinos antes de su institucionalización. Pero como lo resalto, son excepciones. Incluso para quienes defienden la antropología como un campo de la ciencia que valoriza la otredad también has sido criticada de contribuir a la colonialidad del poder sobre esos “otros”. (LATOUR, 1994).
} 
a la necesidad de tener un pensamiento propio para defender los proyectos de vida de las comunidades, donde existe una estrecha relación de este proyecto de vida, con el proyecto político e intelectual de las mismas (ESCOBAR, 2010). De acuerdo con esto, para el modo de producción comunitario el énfasis en la producción de conocimiento es una de las primeras condiciones de la resistencia, que les permite diferenciarse y evitar reproducir el pensamiento dominante contra el cual están luchando. Otros trabajos muestran cómo las políticas públicas de salud han sido influenciadas por lo que han denominado epidemiologia popular y que se refiere al proceso de las comunidades para recolectar, sistematizar, analizar y producir información sobre enfermedades respiratorias o enfermedades asociadas a tóxicos como el mercurio (CORBURN, 2005, 2007; HESS et al., 2008; PORTO; FINAMORE, 2012; CONDE, 2014).

El conocimiento local se revela y es construido, según Corburn, cuando los locales sienten que los análisis de los científicos han retratado incorrectamente su experiencia o cuando se produce la confrontación para que los locales puedan obtener algo de control de la situación. Para aproximarse a una caracterización de lo que significa el conocimiento local Corburn lo hace al realizar cinco preguntas sobre el conocimiento y compararla entre lo que considera el conocimiento local y el profesional (Cuadro 3). Aclara que de todas formas no hace una separación radical de lo que es conocimiento local de conocimiento profesional, sino que este tipo de distinción son marcos adecuados para capturar diferentes aproximaciones de la producción de conocimiento. Por lo tanto, este autor prefiere no dar una definición acabada de "conocimiento local”, en su lugar, va a resaltar las diferencias entre éste y el conocimiento profesional. Estas diferencias se pueden indagar a partir de 5 preguntas que indagan por el sujeto que conoce, cómo 
se adquiere ese conocimiento, qué tipo de evidencia construye, cómo se valida y cuál es su utilidad para la acción.

Cuadro 3. Conocimiento local vs. conocimiento profesional

\begin{tabular}{|c|c|c|}
\hline $\begin{array}{l}\text { Preguntas } \\
\text { claves }\end{array}$ & Conocimiento local & $\begin{array}{l}\text { Conocimiento } \\
\text { profesional }\end{array}$ \\
\hline $\begin{array}{l}\text { ¿Quién tiene } \\
\text { el conoci- } \\
\text { miento }\end{array}$ & $\begin{array}{l}\text { Miembros de la } \\
\text { comunidad, a menudo } \\
\text { grupos identitarios de } \\
\text { lugares específicos }\end{array}$ & $\begin{array}{l}\text { Miembros de una } \\
\text { profesión, universidades, } \\
\text { industria, instituciones } \\
\text { estatales y en ocasiones } \\
\text { ONG's }\end{array}$ \\
\hline $\begin{array}{l}\text { ¿Cómo es } \\
\text { adquirido el } \\
\text { conocimien- } \\
\text { to? }\end{array}$ & $\begin{array}{l}\text { A través de la experiencia } \\
\text { y de la tradición cultural }\end{array}$ & $\begin{array}{l}\text { Estudios experimentales, } \\
\text { métodos epidemiológicos }\end{array}$ \\
\hline $\begin{array}{l}\text { ¿Qué hace a } \\
\text { esa } \\
\text { evidencia } \\
\text { creíble? }\end{array}$ & $\begin{array}{l}\text { Evidencia a simple vista, } \\
\text { experiencia de vida, no es } \\
\text { necesariamente } \\
\text { dependiente de } \\
\text { instrumentos. }\end{array}$ & $\begin{array}{l}\text { Mediado por el uso de } \\
\text { instrumentos, la estadística, } \\
\text { estándares legales }\end{array}$ \\
\hline $\begin{array}{l}\text { ¿Cómo se } \\
\text { valida el co- } \\
\text { nocimiento } \\
\text { producido }\end{array}$ & $\begin{array}{l}\text { Narrativas públicas, } \\
\text { historias comunitarias, } \\
\text { tribunales, medios de } \\
\text { comunicación. }\end{array}$ & $\begin{array}{l}\text { Revisión por pares, cortes, } \\
\text { medios de comunicación }\end{array}$ \\
\hline $\begin{array}{l}\text { ¿Qué tipo de } \\
\text { orientación } \\
\text { toma para la } \\
\text { acción? }\end{array}$ & $\begin{array}{l}\text { Precaución/prevención; el } \\
\text { consenso sobre las causas } \\
\text { no es necesario. }\end{array}$ & $\begin{array}{l}\text { Consenso científico sobre } \\
\text { factores causales }\end{array}$ \\
\hline
\end{tabular}

Fuente: Corburn, 2005.

Como se intuye del cuadro anterior, el conocimiento local, sus fuentes y sus productos están anclados a redes de producción muy diferentes de las redes de producción de conocimiento científico. Mientras que en este último nos movemos por instituciones, profesiones, sistema de pares para construir la autoridad científica y el uso de estándares; en el conocimiento local la red es el individuo, el sistema 
de normas sociales, la experiencia, los métodos propios o apropiados de observación y medición. Se incluye en el conocimiento local las asociaciones para la movilización del conocimiento y el cómo son utilizadas historias y experiencias para crear narrativas locales, también las estrategias y métodos mediante los cuales las personas empiezan a entrenarse en técnicas científicas, en cómo recolectar, analizar e inferir información y, además, cómo el conocimiento local viaja a través de dominios tradicionales de experticia.

Aunque en realidad ningún conocimiento no esté situado o anclado a un lugar, con la forma de producción de conocimiento local/comunitario quiero destacar la forma en que grupos de personas detentan un conocimiento arraigado en un lugar geográfico determinado y en su relación con dicho lugar. Es un conocimiento que es constituido por la experiencia y la práctica, que tiene un gran componente tácito y que pasa por procesos de reflexión y codificación como resultado de procesos de contestación, pero que en cierta medida el conocimiento local depende de la existencia de lo comunitario (relación individuo, grupo, lugar, actividad) (KUSCH, 2002). Para el proceso de codificación, circulación y reflexión sobre el conocimiento, los actores comunitarios pueden establecer alianzas con profesionales y centros de producción de conocimiento científico, pueden desarrollar sus propios métodos de observación, recolección y análisis de la información; o pueden hacer una mezcla de ambas mediante metodologías de Investigación-Acción-Participación. (BONILLA et al., 1972). 


\section{Producción y movilización de conocimiento en conflictos socioambientales}

La literatura sobre conflictos socioambientales estudia los factores sociales, ambientales, económicos y culturales de los conflictos de distribución ecológica. Trabajos como los desarrollados por MartínezAlier y su equipo de investigación, se han encargado de mapear ${ }^{12}$ los conflictos socioambientales alrededor del mundo y estudiar su relación con el metabolismo social que los genera (TEMPER, 2014; MARTÍNEZ-ALIER, 2015; TEMPER; BENE; MARTINEZ-ALIER, 2015). ${ }^{13}$ De acuerdo con Joan Martínez-Alier, existe una relación dinámica y dialéctica entre académicos y activistas enfocada en los conflictos de distribución ecológica mediante un proceso interactivo entre la producción de conocimiento y el uso del conocimiento (MARTÍNEZALIER et al., 2011, 2014). En su trabajo, Martínez-Alier estudia la coproducción a partir de conceptos que son trasladados del campo académico al campo activista, y viceversa, a partir de una interrelación de trabajo y de confianza entre académicos y activistas. Estos trabajos nos muestran que los conflictos socioambientales son lugares importantes para la producción y movilización de conocimiento. Como se mostró en la sección anterior, el conocimiento no se refiere solamente al conocimiento científico, sino también, al conocimiento local y al conocimiento activista, entre otros.

La configuración del espacio de conflicto se establece mediante la oposición de múltiples actores, las alianzas que establecen entre sí

\footnotetext{
${ }^{12}$ Se puede consultar el Atlas mundial de conflictos. Disponible en: ejatlas.org.

${ }^{13}$ Este tipo de análisis muestra las características de los conflictos, su intensidad, la resistencia comunitaria, los tipos de acciones, los actores y los resultados en términos de la justicia ambiental. Algunos de ellos han mostrado la relación entre el activismo y la ciencia y su relación con procesos de participación pública en asuntos ambientales.
} 
para constituir narrativas y las respuestas que dan a los demás actores. Es por tanto un proceso dinámico que permite, por ejemplo, la aparición, consolidación y modificación de actores en las arenas ambientales. En este sentido, Merlinsky reporta que es muy frecuente que el movimiento de resistencia no exista con anterioridad a la acción colectiva que se da dentro del conflicto socioambiental, lo que hay son grupos de sociabilidad y proximidad que cumplen un rol importante en la difusión de la movilización y que, sin embargo, no la anteceden como colectivo, sino que se forman en el contexto particular del proceso contencioso mismo (MERLINSKY, 2013, p. 61). ${ }^{14}$

El conflicto socioambiental permite la emergencia de redes de producción y movilización de conocimiento, más allá de las redes oficiales y sus políticas públicas. Hay un conocimiento oficial que, a través de políticas públicas estatales se ancla socialmente. Es un conocimiento alineado con ciertas instituciones y con determinadas narrativas. Un conocimiento-red que privilegia las decisiones centralizadas, la aplicación de teorías económicas complejas, como instrumentos estandarizados que gozan de reputación, se insertan en ciertas burocracias y parecen universales. Por ejemplo, Asher y Ojeda (2014) nos muestran cómo en el caso del Chocó se aplican las técnicas de ordenamiento territorial aunado a un discurso científico de la clasificación, aprovechamiento e incursión de la naturaleza en el mercado. En la misma vía, Del Cairo (2019) discute cómo las políticas públicas de conservación para la Amazonía colombiana, apoyadas en el conocimiento científico-experto, producen categorizaciones para definir qué es un sujeto ambiental deseable y productivo, y en ese proceso, crean las

\footnotetext{
${ }^{14}$ Muchas de las luchas territoriales que nacen como redes de producción comunitarias pueden articularse con movimientos y redes de justicia ambiental como Movimientos Ríos Vivos (Colombia), Movimento dos Atingidos por Barragens (Brasil), AIDA-Asociación Interamericana de Defensa del Medio Ambiente.
} 
condiciones y criterios para definir quién puede o no pertenecer a un lugar, lo que justifica el despojo y la exclusión de comunidades que no se alineen con los dispositivos estatales (discursos, prácticas y burocracias), por ejemplo, de sostenibilidad y conservación.

Lo que muestran los conflictos socioambientales, es que la ciencia y sus conocimientos-red no son suficientes en situaciones complejas como la negociación sobre los territorios y las posibilidades de vivir vidas dignas en dichos territorios. En el caso del Chocó la comprensión de lo que significaba el derecho étnico de los pueblos afrocolombianos y la biodiversidad difería en gran medida entre las instituciones gubernamentales y las comunidades raizales ${ }^{15}$ (ASHER; OJEDA, 2014). En la discusión sobre la protección de ecosistemas estratégicos en Colombia, como son los páramos, y el aprovechamiento de los recursos mineros, Parra-Romero y Gitahy muestran cómo se conformó un movimiento social en torno a la protección del páramo de Santurbán y, a partir de este conflicto, se complejizó la negociación sobre la apuesta nacional para hacer o no minería a gran escala y la protección de las fuentes hídricas (PARRA-ROMERO; GITAHY, 2017).

El conocimiento no es algo que simplemente produzca una persona, es decir, que opere exclusivamente en el ámbito de lo personal o sólo una institución. El conocimiento científico requiere de redes que posibiliten su producción: instituciones de financiación, centros de cálculo, investigadores y prácticas específicas de producción de conocimiento (LATOUR, 1992). De la misma manera, otras formas de producir conocimiento, como el activista y el conocimiento local, no se producen solamente como el resultado de una experiencia personal, de una sola forma de ver y comprender el entorno o un problema. Sino

\footnotetext{
${ }^{15}$ Un movimiento social que se consolida en este período (años 90) es el Proceso de Comunidades Negras (PCN). Para ver: renacientes.net.
} 
que está totalmente relacionado con las posibilidades para que se conecten personas, organizaciones y formas de aprender-hacer, al igual que diferentes estrategias para abordar los problemas que se representan para las comunidades, activistas o locales. Constituyendo, así, comunidades de práctica donde se pone en juego no sólo las formas explicitas y tácitas del conocimiento sino las condiciones materiales que posibilitan las redes donde emergen las relaciones para producir conocimiento.

La forma en que los distintos actores enmarcan el conflicto y sus actuaciones responden a un proceso, no necesariamente consciente y estratégico, en el que dan una importancia mayor a ciertos aspectos del conflicto sobre otros. Estos actores y los aspectos a los que dan mayor importancia, se constituyen en redes de conocimiento que producen y movilizan conocimiento para ganar posiciones en el conflicto. Como producto de la movilización de dichos enfoques (frames) se construyen narrativas. Por ejemplo, Parra-Romero y Gitahy analizan cómo el movimiento social en defensa del páramo de Santurbán adjudica como una victoria del movimiento el hecho de enmarcar el problema de la megaminería como un asunto de la defensa del agua y no como una cuestión de resistencia contra la minería (PARRA-ROMERO; GITAHY, 2017). Sin embargo, la producción de narrativas no es exclusiva de los movimientos sociales. Empresas, gobiernos y organizaciones también construyen narrativas como parte del conflicto. Por ejemplo, el neoliberalismo también crea narrativas que dan forma a diferentes demandas epistemológicas que son introducidas y adoptadas por los productores del conocimiento como las universidades y los centros de investigación asociados al Estado (LAVE, 2012). En este sentido, la modernidad, la globalización o el desarrollo son también narrativas de pretensión universal (JASANOFF, 2004). En las 
controversias y debates del conflicto, no sólo cada narrativa provee un enfoque diferente (frame) del problema, sino que los actantes, conocimientos, y redes bajo las cuales se moviliza el conocimiento son diferentes.

El conflicto socioambiental es por tanto una posibilidad para disputar, pero también para producir. En este caso, producir conocimientos sobre distintos aspectos del conflicto por distintos actores. Lo que permite que se pongan en juego experticias que contribuyen al cambio social. Los diferentes modos de producción traen asociados las formas tácitas de conocimiento que podemos denominar como experticia. Una activista por el agua de Colombia hizo la siguiente pregunta en un evento: ¿han visto cuánto sabe un activista y cuánto sabe un científico sobre el mismo fenómeno? La respuesta a la primera parte es la experticia comunitaria y activista; la respuesta a la segunda es la experticia científica. Cuando los activistas estudian el EIA (Estudio de Impacto Ambiental), realizan interpretaciones de la información y discuten los escenarios ambientales ganan experticia científica. Cuando un científico camina el páramo, se interesa realmente por entender la explicación del minero, por acompañar, por dialogar más allá del mapa y sí comprendiendo/sintiendo la relación socavón/línea, oficio y dignidad, el científico gana experticia consuetudinaria.

La experticia científica contribuye a la estandarización del conocimiento y por tanto hacer más fuertes los vínculos de la red que los moviliza. La experticia jurídica, bastante movilizada por los movimientos sociales en temas ambientales, tiene una fuerte relación con anclar el conocimiento que surge en el contexto del conflicto; la experticia activista contribuye en la producción de contenidos nuevos y anclados en tiempos menores que con otras experticias; y la experticia local (relacionada con el conocimiento comunitario) avanza en la construc- 
ción de capacidades políticas y de movilización de las comunidades. El conocimiento local (que puede ser comunitario o activista o ambos) incorpora otros elementos importantes como la identidad social y su anclaje al lugar. En este aspecto, trae consigo valores, experiencias, historias y narrativas, que al igual que el conocimiento científico, son renegociados cuando en los lugares donde se produce emergen nuevos riesgos, experiencias o contingencias. También este tipo de conocimiento ayuda a mostrar los límites - muchas veces desafiándolo - del conocimiento científico y especializado, lo que ayudaría a los profesionales a trabajar por una producción de conocimiento más contextualizada (CORBURN, 2005; PORTO, 2012).

En esta medida, las experticias y los modos de conocimiento, al igual que las redes que los producen en el contexto del conflicto socioambiental, ayudan a la creación de nuevas categorías sociales y políticas. Por ejemplo, Martínez-Alier et al. (2011) presenta cómo el concepto de deuda ecológica acuñado por activistas desde 1990, en protesta a la dificultad que tienen algunos países del sur para pagar su deuda externa; es explícitamente introducido en otros discursos académicos y de líderes políticos. A este caso le llama una ciencia liderada por el activismo. Para el caso contrario, el activismo liderado por la ciencia, presenta el caso del EROI (Energy Return on Energy Input), concepto de la economía ecológica que es introducido en el discurso y las demandas de los activistas de la Vía Campesina, sus organizaciones y sus redes para mejorar sus capacidades y fortalecer sus argumentos (MARTÍNEZ-ALIER et al., 2011). Estos ejemplos nos muestran que las categorías nacen cuando son necesarias socialmente (FOUREZ, 2000) y, en esta medida, el conflicto y su dinámica promueven, mediante la producción y movilización de conocimiento, que conceptos como deuda ecológica (MARTÍNEZ-ALIER et al., 
2011), minería ancestral, páramos como fábricas de agua (PARRAROMERO; GITAHY, 2017; PARRA-ROMERO, 2019) o licencia social (PRNO; SCOTT SLOCOMBE, 2012; COSTANZA, 2016) emerjan para disputar otros conceptos y categorías hegemónicas como licencia ambiental, reservas mineras y crecimiento económico, entre otros (ESLAVA et al., 2014; ALZATE GÓMEZ, 2015; ANDRADESASTOQUE; JIMÉNEZ BECERRA, 2016).

\section{Funciones del conocimiento local/comunitario/ activista en los conflictos socioambientales}

El conocimiento y su construcción desde lo comunitario y desde el activismo no solo cumple un papel instrumental (qué investigo) sino también una función política, ontológica y ética. En lo político, el conocimiento es producido/movilizado como una forma de subvertir y trascender el discurso de los detentores del poder (hegemonía) a través de la resignificación de los contenidos e implicaciones de los símbolos socialmente aceptados o rechazándolos y proponiendo otros (COY; WOEHRLE; MANEY, 2008). De esta forma, el conocimiento oposicional sería la manera en que los conocimientos-otros, como parte de un proceso dialógico, son producidos y movilizados para cambiar o modificar la hegemonía dominante (COY; WOEHRLE; MANEY, 2008).

En el campo ontológico del conocimiento los movimientos sociales o los grupos subalternos operarían produciendo discursos que les permitan formular otras interpretaciones sobre sus entidades, intereses y necesidades (CARROLL, 2015). Existe una apuesta por el ser y por la posibilidad de ser de otra forma. Lo ontológico se operacionaliza como una esfera de lo posible: Lo ontológico viene primero 
como un imaginario político que se desarrolla epistemológicamente a través de experiencias de experimentación con formas contra normativas de expresión, relaciones o estilos de vida (CHESTERS, 2012, p. 147). Por ejemplo, una idea de vivir de otro modo en armonía con naturaleza puede llevar a desarrollar y experimentar prácticas de autonomía y soberanía alimentaria, constituir granjas autosostenibles o implementar nuevos métodos agroecológicos. En esta medida, el carácter ontológico del conocimiento producido y movilizado por fuera de la institución científica, se relaciona con ser explícito en los valores, formas de vida y lineamientos sobre cómo deberían o qué se espera de las relaciones sociales para las cuales dicho conocimiento es usado o apropiado socialmente.

Lo ético opera de dos formas, al reconocer las técnicas, los modos de conocer y generar conocimiento en los movimientos sociales. La mayoría de las posturas asumen que hay una persona que sabe y que ilumina al movimiento social, y que si bien estos no lo siguen se debe a apatía o falsa consciencia (CASAS-CORTÉS; OSTERWEIL; POWELL, 2008). Si no se quiere instrumentalizar los movimientos sociales al tratarlos como objetos y no como sujetos, la academia debe avanzar en el reconocimiento de que el activismo social produce "subjetividades críticas cuyo conocimiento contextual y situado es independiente de la academia y tiene valor por sí mismo” (CHESTERS, 2012). Así, debe asumir una postura ética al reconocer el carácter relacional y reciproco con otros sistemas de conocimiento diferentes a la ciencia. El segundo aspecto ético, es la apuesta de muchas comunidades y movimientos sociales por una producción de conocimiento que reconozca el lugar de enunciación y la importancia de conocimientos parciales, situados y contextuales. Es una lucha que intenta disminuir las brechas sociales, aumentar la participación de las comunidades y 
contribuir a la disminución de las injusticias epistémicas (FRICKER, 2007; SANTOS, 2010)

La combinación de lo que Carroll denomina modos de praxiscognitiva, integraría las funciones anteriormente descritas, a la vez que produce conocimiento transformador y transformaciones basadas en el conocimiento (CARROLL, 2015). Así, los grupos (ONG's, fundaciones,) en conjunto con comunidades subalternas y movimientos sociales construyen, a través de los modos de praxis-cognitiva, un conocimiento contrahegemónico basado en formas diferentes de integrar teoría, práctica y diálogo. Algunos de los tipos de conocimiento que integran las funciones políticas, éticas y ontológicas son presentados en el Cuadro 4.

Cuadro 4. Función y tipos de conocimientos locales/activistas/comunitarios

\begin{tabular}{|l|l|}
\hline $\begin{array}{l}\text { Fun- } \\
\text { ción/tipo }\end{array}$ & Definición \\
\hline $\begin{array}{l}\text { Conocimien- } \\
\text { to contra } \\
\text { informativo }\end{array}$ & $\begin{array}{l}\text { Cuenta la historia no contada (la otra versión). Ayuda a } \\
\text { mostrar, al mismo tiempo, a mostrar cómo la } \\
\text { información disponible ha sido seleccionada de forma } \\
\text { selectiva y conveniente; y resalta cómo otras } \\
\text { informaciones deben ser consideradas. }\end{array}$ \\
\hline $\begin{array}{l}\text { Interpreta- } \\
\text { ción } \\
\text { crítica }\end{array}$ & $\begin{array}{l}\text { Evalúa la información que ha sido presentada como } \\
\text { "precisa”, pero cuestiona las bases morales y sociales de } \\
\text { cómo la información es presentada, interpretada y usada. } \\
\text { Muchas veces presenta una definición alternativa al } \\
\text { discurso oficial. }\end{array}$ \\
\hline $\begin{array}{l}\text { Visionario } \\
\text { radical }\end{array}$ & $\begin{array}{l}\text { Visualización sobre los principios o asuntos principales } \\
\text { para intentar el cambio social. El objetivo es plantear } \\
\text { cuáles son las alternativas y cómo podría ser la sociedad } \\
\text { si esos principios visualizados son establecidos. Este } \\
\text { tipo de conocimiento incluye también el conocimiento } \\
\text { contra informativo y la interpretación crítica. }\end{array}$ \\
\hline
\end{tabular}




\begin{tabular}{|l|l|}
\hline $\begin{array}{l}\text { Transformati- } \\
\text { vo }\end{array}$ & $\begin{array}{l}\text { Este tipo de conocimiento define caminos o vías } \\
\text { alternativas para instaurar la visión alternativa } \\
\text { visualizada por los movimientos sociales. }\end{array}$ \\
\hline $\begin{array}{l}\text { Desafiar el } \\
\text { conocimiento } \\
\text { hegemónico }\end{array}$ & $\begin{array}{l}\text { Disrupción y cuestionamiento del sentido común } \\
\text { hegemónico a través de la investigación académica } \\
\text { crítica y otras prácticas. }\end{array}$ \\
\hline $\begin{array}{l}\text { Movilizar } \\
\text { conocimiento } \\
\text { alternativo }\end{array}$ & $\begin{array}{l}\text { Aplicando estrategias para comprometer instituciones } \\
\text { desde una postura opuesta a la oficial, aplicando } \\
\text { algunas estrategias de diálogo y negociación al interior } \\
\text { de estas instituciones. Se complementa con otros tipos } \\
\text { de movilización política como las protestas, la } \\
\text { estrategia de medios y con la influencia de personas } \\
\text { claves en instituciones de "poder” }\end{array}$ \\
\hline $\begin{array}{l}\text { Empoderar or- } \\
\text { ganizaciones } \\
\text { de base }\end{array}$ & $\begin{array}{l}\text { Incentivar las capacidades comunitarias y de activismo. } \\
\text { Existencia de intelectuales orgánicos que producen su } \\
\text { propio conocimiento como base de una agencia } \\
\text { colectiva transformativa a través de la participación y } \\
\text { la construcción de capacidades. }\end{array}$ \\
\hline $\begin{array}{l}\text { Construir } \\
\text { solidaridades }\end{array}$ & $\begin{array}{l}\text { Se realiza a través del diálogo con otros actores. Tiene } \\
\text { como objetivo que haya una convergencia entre las } \\
\text { estrategias, la organización y la visión. De lo contrario } \\
\text { el conocimiento contrahegemónico quedaría escondido } \\
\text { o sin uso; y la resistencia aparecería ante el status quo } \\
\text { como episódica sin alternativas reales. }\end{array}$ \\
\hline $\begin{array}{l}\text { Integración } \\
\text { de la teoría y } \\
\text { la práctica }\end{array}$ & $\begin{array}{l}\text { Parte de la idea de una dialéctica entre teoría y práctica. } \\
\text { El conocimiento práctico y vivencial de los activistas } \\
\text { trata de cambiar al mundo y el conocimiento teórico } \\
\text { intenta mejorar la comprensión de cómo el mundo está } \\
\text { estructurado y cómo puede ser transformado. Al } \\
\text { mismo tiempo se requiere que los teóricos construyan } \\
\text { su conocimiento con una fuerte base empírica como la } \\
\text { de los activistas. }\end{array}$ \\
\hline
\end{tabular}




\begin{tabular}{|l|l|}
\hline $\begin{array}{l}\text { Creación de espacios } \\
\text { de reflexión e } \\
\text { invención }\end{array}$ & $\begin{array}{l}\text { Es importante crear espacios para que nuevas } \\
\text { ideas puedan surgir y donde se permita el } \\
\text { encuentro de la teoría y la práctica. Estos } \\
\text { espacios permiten que los movimientos y las } \\
\text { personas reflexionen sobre "lo que conocen, lo } \\
\text { que pueden hacer y cuáles son las bases sobre } \\
\text { las que pueden actuar" }\end{array}$ \\
\hline $\begin{array}{l}\text { Sistematización y } \\
\text { diseminación de } \\
\text { conocimiento } \\
\text { alternativo }\end{array}$ & $\begin{array}{l}\text { La sistematización del conocimiento alternativo } \\
\text { es una manera de darle fuerza, poderlo } \\
\text { comparar y aplicar - de ser necesario - en otros } \\
\text { contextos. Algunas de las formas para hacerlo } \\
\text { son el libro, cartillas o portales virtuales. }\end{array}$ \\
\hline $\begin{array}{l}\text { Prefiguración de } \\
\text { futuros alternativos } \\
\text { desde las prácticas } \\
\text { actuales. }\end{array}$ & $\begin{array}{l}\text { Para producir conocimiento alternativo se debe } \\
\text { ir más allá de criticar las prácticas existentes. } \\
\text { Identificar en el presente las potencialidades } \\
\text { para vivir de otro modo, cómo se pueden } \\
\text { fortalecer esas potencialidades y movilizar el } \\
\text { conocimiento alternativo hacia comunidades y } \\
\text { públicos amplios que permitan crear un sentido } \\
\text { común y vayan convirtiendo en una posibilidad } \\
\text { esos futuros alternativos. }\end{array}$ \\
\hline
\end{tabular}

Fuente: basado en Coy, Woehrle y Maney (2008) y Carroll (2015).

\section{Consideraciones finales}

Los conflictos socioambientales son espacios importantes que, como lo ha mostrado la ecología política, representan los problemas de carácter distributivo de los recursos naturales, las luchas de poder y las injusticias de carácter ambiental asociados a formas específicas de relaciones sociedad-naturaleza. En este trabajo, mostramos cómo los diferentes actores que se enfrentan en los conflictos pueden hacer uso de diferentes modos de producción y movilización de conocimiento para defender su postura.

Presentamos y discutimos el modo científico, el activista y el local/comunitario. Estos modos hablan de las formas, prácticas y articu- 
laciones que distintos actores pueden realizar para conocer. Hablar de conocimiento implica ir más allá de lo que significa el conocimiento formal y su red de instituciones. El conocer no es una habilidad que sea exclusiva de una actividad humana como la ciencia. El conocer es una habilidad que denota acción y que se relaciona con todas las actividades humanas. Y es en lo conflictos socioambientales que encontramos diversas formas, fuentes de conocer los territorios, la naturaleza y las relaciones de ésta con humanos y no humanos. Las formas de producción son complementarias y necesarias. Tanto el conocimiento activista como el conocimiento científico aportan elementos concretos y complementarios al momento de gestionar los territorios.

El espacio del conflicto permite, entonces, desarrollar, movilizar y potencializar no solo el conocimiento de diversos colectivos, sino también diferentes experticias que contribuyen al cambio social. No solo se lucha por la justicia ambiental, sino que estas luchas, representan un avance en dar voz a sectores y poblaciones que de lo contrario estarían excluidas de la toma de decisiones y de las redes de producción hegemónicas. Es en esta vía que los conflictos socioambientales no solo contribuyen a la justicia ambiental sino también a la justicia epistémica. Son fuerzas para la sustentabilidad, promueven la producción de conocimiento no hegemónico y ejercen presión para negociar y ampliar/ mejorar la gobernanza.

No se trata de quitar el valor del conocimiento científico. Incluso requerimos más ciencia y mejores modelos de divulgación en ciencias naturales y en ciencias sociales, para que a nivel de opinión pública quienes pretenden apelar a la autoridad científica para justificar, por ejemplo, el uso de agroquímicos para erradicación de cultivos iliciticos, o el uso de medidas autoritarias para legitimar la conservación, puedan realizar una crítica y ver los problemas de dicha ciencia y la 
forma en que es usada por ciertas narrativas institucionales. Casos como el del Chocó, y muchos otros, nos hablan de cómo las decisiones siguen pasando por las redes de producción hegemónica y oficial: instituciones gubernamentales, universidades y centros de investigación con prestigio donde los actores comunitarios y activistas no son reconocidos; y cuando el conflicto escala, son incluidos en formas instrumentales de participación.

Lo que queremos resaltar es que se puede llevar una visión del conflicto en que reconozcamos diversos antagonistas y que las discusiones, decisiones y transformaciones que sufran dichos conflictos, sean el resultado de procesos de participación y negociación más justos. Donde se reconozca los diferentes niveles y tipos de experticias y conocimientos que resultan de diferentes narrativas. El conocimiento de los movimientos sociales y de las comunidades operarían en dos sentidos: el primero da cuenta de lo que es y el segundo de lo que podría ser (otro mundo posible), como epistemología alternativa, este conocimiento local puede contribuir a análisis técnicos complejos y en decisiones políticas. Es decir, no sólo podría operar en una esfera instrumental de participación ciudadana, sino que se requiere para coproducir una gestión de los territorios y de los ecosistemas y avanzar hacia cambios sociales importantes en esos aspectos.

\section{Referencias}

ALZATE GÓMEZ, L. F. Minería de oro en el marco de la inseguridad normativa, los grupos de interés y las zonas de exclusión. Revista Opinión Jurídica, v. 14, n. 28, p. 117-133, 2015.

ANDRADE-SASTOQUE, E.; JIMÉNEZ BECERRA, J. A. Trayectoria Socio-Técnica de las Relaciones entre Extractivismo y Desarrollo Sostenible: el Caso de la Colosa en Colombia. Revista REDES, v. 22, n. 43, p. 33-64, 
2016.

APARICIO, J. R.; BLASER, M. The "Lettered City" and the Insurrection of Subjugated Knowledges in Latin America. Anthropological Quarterly, v. 81, n. 1, p. 59-94, 2008.

ASHER, K.; OJEDA, D. Producir la naturaleza y hacer el Estado: el ordenamiento territorial en las tierras bajas del Pacífico colombiano. In: ESPINOSA, M.; BETANCOUR, A. (Ed.). El poder en plural: entre la antropología y la teoría política. Bogotá, Colombia: Ediciones UniAndes, 2014. p. 149-175.

ATLAS mundial de conflictos. Disponible en: ejatlas.org.

BEBBINGTON, A. Minería, movimientos sociales y respuestas campesinas: una ecología política de transformaciones territoriales. Peru: IEP, Instituto de Estudios Peruanos, 2007. Serie: Minería y Sociedad 2.

BHAMBRA, G. Postcolonial and decolonial dialogues. Postcolonial Studies, v. 17 (2), 115-12, 2014.

BLASER, M. ¿Es otra cosmopolítica posible? Anthropologica, v. 36, n. 41, p. 115-144, 2018.

BLASER, M. Notes Towards a Political Ontology of "Environmental” Conflicts. In: GREEN, Lesley (Ed.). Contested Ecologies: dialogues in the south on nature and knowledge. Cape Town: HSRC Press, 2013. p. 13-27.

BONILLA, V.; CASTILLO, G.; FALS BORDA, O.; LIBREROS, A. Causa popular, ciencia popular. [s.l.]: Publicaciones de la Rosca, v. 1, 1972.

BOSWELL, Christina. The Political Uses of Expert Knowledge: Immigration Policy and Social Research. Cambridge, GB: Cambridge University Press, 2009

BRIGGS, J. Indigenous knowledge: a false dawn for development theory and practice? Progress in Development Studies, v. 13, n. 3, p. 231-243, 9 jul. 2013.

CALLON, M. The Role of lay people in the production and dissemination of scientific knowledge. Science Technology \& Society, v. 4, n. 1, p. 81-94, 1999.

CALLON, M.; RABEHARISOA, V. Research "in the wild" and the shaping of new social identities. Technology in Society, v. 25, n. 2, p. 193-204, 2003.

CARROLL, William K. Modes of Cognitive Praxis in Transnational Alter- 
native Policy Groups. Globalizations, v. 12, n. 5, p. 710-727, 2015.

CASAS-CORTÉS, María Isabel. Social Movements as Sites of Knowledge Production: Precarious Work, the Fate of Care and Activist Research in a Globalizing Spain. 2009. 519 f. University of North Carolina at Chapel Hill, 2009.

CASAS-CORTÉS, M. I.; OSTERWEIL, M.; POWELL, D. E. Blurring boundaries: recognizing knowledge-practices in the study of social movements. Anthropological Quarterly, v. 81, n. 1, p. 17-58, 2008.

CASTRO-GÓMEZ, S.; GROSFOGUEL, R. El giro decolonial. Reflexiones para una diversidad epistémica más allá del capitalismo global. Bogotá, Colombia: Siglo del Hombre Editores, 2007.

CHESTERS, G. Social movements and the ethics of knowledge production. Social Movement Studies, v. 11, n. 2, p. 145-160, abr. 2012.

CHOUDRY, A. Activist research and organizing: blurring the boundaries, challenging the binaries. International Journal of Lifelong Education, v. 33, n. 4, p. 472-487, 2014.

CONDE, M. Activism mobilising science. Ecological Economics, v. 105, p. 67-77, 2014.

CORBURN, J. Environmental justice, local knowledge, and risk: the discourse of a community-based cumulative exposure assessment. Environmental Management, v. 29, n. 4, p. 451-466, 2002.

. Bringing local knowledge into environmental decision making. Journal of Planning Education and Research, v. 22, n. August, p. 420-433, 2003.

. Street science: community knowledge and environmental health justice. [s.l.]: The MIT Press, 2005.

- Community knowledge in environmental health science: coproducing policy expertise. Environmental Science and Policy, v. 10, n. 2, p. 150-161, 2007.

COSTANZA, J. N. Mining conflict and the politics of obtaining a social license: insight from Guatemala. World Development, v. 79, p. 97-113, 2016.

COX, L. Movements making knowledge: a new wave of inspiration for Sociology? Sociology, v. 48, n. 5, p. 954-971, 2014.

COX, L.; FOMINAYA, C. F. Movement knowledge: what do we know, how 
do we create knowledge and what do we do with it? Interface: A Journal for and About Social Movements, v. 1, n. 1, p. 1-20, 2009.

COY, P. G.; WOEHRLE, L. M.; MANEY, G. M. A typology of oppositional knowledge: Democracy and the U.S. peace movement. Sociological Research Online, v. 13, n. 4, 2008.

DE LA CADENA, M. Indigenous cosmopolitics in the Andes: conceptual reflections beyond "Politics." Cultural Anthropology, v. 25, n. 2, p. 334-370, maio 2010.

. Earth beings. Ecologies of practice across andean worlds. Durham, US: Duke University Press, 2015.

DEL CAIRO, Carlos. Selvas y gentes (in)cultas: políticas de la cultura y poblaciones amazónicas en los diseños de intervención estatal. Cultura: centralidad, artilugios, etnografía. Colección. [s.l.]: Asociación Colombiana de Antropología, 2019. p. 107.

ESCOBAR, A. Whose knowledge, whose nature? Biodiversity, conservation, and the political ecology of social movements. Journal of Political Ecology, v. 5, p. 53-82, 1998.

. El lugar de la naturaleza la naturaleza del lugar. In: LANDER, E. La colonialidad del saber: eurocentrismo y ciencias sociales. Perspectivas latinoamericanas. Buenos Aires: CLACSO, Consejo Latinoamericano de Ciencias Sociales, 2000.

. Territorios de diferencia: lugar, movimientos, vida, redes. [s.l.]: Envión Editores, 2010.

ESLAVA, A.; GIRLADO, J.; GONZÁLEZ, A. C.; HILLON, Y.; RIOS, A.; SILVA, S.; ZAPATA, O.; CORREA, L.; PRECIADO, A.; TRUJILLO, J. P. Oro como fortuna. Instituciones, capital social y gobernanza de minería aurífera colombiana. Medellin, Colombia: Centro de Análisis Político - Departamento de Gobierno y Ciencias Políticas - Universidad EAFIT, 2014.

FOUREZ, G. La construcción del Conocimiento Científico. Sociología y ética de la ciencia. [s.l.]: Segunda Ed ed. Narcea, S.A Ediciones, 2000.

FRICKER, M. Epistemic injustice. Power \& the ethics of knowing. [s.l.]: Oxford University Press, 2007.

GIBBONS, M.; LIMOGES, C.; NOWOTNY, H.; SCHWARTZMAN, S.; SCOTT, P.; TROW, M. The new production of knowledge. The dynamics 
of science and research in contemporary societies. London, England: SAGE Publications, 1994.

GOHN, Maria da Glória. Teorias dos movimentos sociais: paradigmas clássicos e contemporâneos. São Paulo: Edições Loyola, 5a . Edição, 2006.

GUDYNAS, E. Conflictos y extractivismos: conceptos, contenidos y dinamicas. DECURSOS, Revista en Ciencias Sociales, n. 27-28, p. 79-115, 2014.

HALL, B. L.; CLOVER, D. E.; CROWTHER, J.; SCANDRETT, E. Learning and education for a better world: The role of social movements. Sense Publishers, 2012

HESS, David et al. Science, technology, and social movements. In: HACKETT, Edward J. et al. (eds.). The handbook of science and technology studies. Third. 2008. p. 1025.

HOSSEINI, S A Hamed. Activist Knowledge: Interrogating the Ideational. The International Journal of interdisciplinary Social Science, v. 5, n. 5, p. 339-357, 2010.

JAMISON, Andrew. The shaping of global environmental agenda: the role of Non-Governmental Organizations. In: LASH, SCOTT; SZERSZYNSKI, BRONISLAW ; WYNNE, Brian (ed.). Risk, environment \& modernity. Towards a new ecology. SAGE Publi. London, England: [s. n.], 1998. p. 287.

. The making of green knowledge: environmental politics and cultural transformation. Cambridge, GB: Cambridge University Press, 2001.

. Social movements and science: cultural appropriations of cognitive praxis. Science as Culture, v. 15, n. 1, p. 45-59, Mar. 2006.

JASANOFF, Sheila. States of knowledge: the co-production of science and social order. International Library of Sociology, 2004.

KUSCH, Martin. Knowledge by Agreement: The Programme of Communitarian Epistemology. [s.l.]: Oxford University Press, 2002.

LATOUR, Bruno. Jamais fomos modernos: ensaio de antropologia simétrica. 1st ed. Rio de Janeiro: Coleção TRANS, Editora 34, 1994.

. Ciência em Acão. Como seguir cientistas e engenheiros sociedade afora. Traducão de Ivone C. Benedettí; revisão de tradução Jesus de Paula Assis. São Paulo: Editora UNESP, 2000.

LAVE, R. Neoliberalism and the Production of Environmental Knowledge. 
Environment and Society, v. 3, n. 1, p. 19-38, 2012.

MARTÍNEZ-ALIER, J. Ecología política del extractivismo y justicia socioambiental. Interdiciplina, v. 3, n. 7, p. 57-73, 2015.

MARTÍNEZ-ALIER, J.; HEALY, H.; TEMPER, L.; WALTER, M.; RODRIGUEZ-LABAJOS, B.; GERBER, J.-F.; CONDE, M. Between science and activism: learning and teaching ecological economics with environmental justice organisations. Local Environment, v. 16, n. 1, p. 17-36, ene. 2011.

MARTÍNEZ-ALIER, Joan et al. Between activism and science: grassroots concepts for sustainability coined by Environmental Justice Organizations. Journal of Political Ecology, v. 21, p. 19-60, 2014.

MCCORMICK, Sabrina. Mobilizing science: movements, participation, and the remaking of knowledge. Philadelphia, US: Temple University Press, 2009.

MENDIOLA Ignacio. Movimientos sociales. Definición y teoría. Barcelona Universitat Oberta de Catalunya. 2002.

MERLINSKY, G. Cartografías del conflicto ambiental en Argentina. CLACSO, Consejo Latinoamericano de Ciencias Sociales, 2013.

MORIN, E. El método 3. El conocimiento del conocimiento. Quinta Edi ed. Madrid, España: Ediciones Cátedra (Grupo Anaya, S.A), 2006.

NONAKA, I.; TAKEUCHI, H. La organización creadora de conocimiento: cómo las compañías japonesas. Oxford Unviersity Prees, p. 60-102, 1999.

NOWOTNY, H.; SCOTT, P.; GIBBONS, M. Re-thinking Science. Knowledge and the public in an age of uncertainty. Polity press, 2001.

OSORIO, C. El modo 2 de investigación: la nueva forma de producción del conocimiento. Heurística 13, p. 3-14, 2005.

OSTERWEIL, M.; ESCOBAR, A. In search of movement [electronic resource] : Italy's movimento dei movimenti, theoretical-practice and re-making the political. 2010.

PAREDES PEÑAFIEL, Adriana Paola; LI, Fabiana. Nourishing Relations: Controversy over the Conga Mining Project in Northern Peru. Ethnos, v. 84, n. 2, p. 301-322, 15 Mar. 2019.

PARRA-ROMERO, A. “Agua sí, oro no”. Producción de una narrativa por la defensa del agua y del páramo de Santurbán (Colombia). In: CASAS, R.; 
PEREZ-BUSTOS, T. (Ed.). Ciencia, tecnología y sociedad en América Latina: la mirada de las nuevas generaciones II. Asociación Latinoamericana de Estudios Sociales de la Ciencia y la Tecnologías-ESOCITE y CLACSO, 2019. p. 417.

PARRA-ROMERO, A.; GITAHY, L. Movimiento social como actor-red: Ensamblando el comité por la defensa del Agua y del Páramo de Santurbán. Universitas humanística, v. 84, 2017.

PESTRE, D. Regimes of knowledge production in society: Towards a more political and social reading. Minerva, v. 41, n. 3, p. 245-261, 2003.

POLANYI, M. Personal knowledge. Towards a post-critical philosophy. [s.l.] Routledge \& Kegan Paul, 1983.

POLANYI, Michael. A dimensão tácita. Inovatec (Portugal), 2010.

PORTO, M. F. Uma ecologia política dos riscos. Princípios para integrarmos o local e o global na promoção da saúde e da justiça ambiental. Rio de Janeiro: Editora Fiocruz, 2012.

PORTO, M. F.; FINAMORE, R. Riscos, saúde e justiça ambiental: o protagonismo das populações atingidas na produção de conhecimento. Ciência \& Saúde Coletiva, v. 17, n. 6, p. 1493-1501, 2012.

PRNO, J.; SCOTT SLOCOMBE, D. Exploring the origins of «social license to operate» in the mining sector: Perspectives from governance and sustainability theories. Resources Policy, v. 37, n. 3, p. 346-357, 2012.

EL PROCESO de Comunidades Negras (PCN). Disponible en: renacientes.net.

SANTOS, B. D. S. Descolonizar el saber, reinventar el poder. Uruguay: Trilce, 2010.

SVAMPA, M. Consenso de los commodities, giro ecoterritorial y pensamiento crítico en América Latina. In: SADER, E.; GENTILI, P. (Eds.). Movimientos socioambientales en América Latina. Buenos Aires: CLACSO Consejo Latinoamericano de Ciencias Sociales, 2012.

. Las fronteras del neoextractivismo en América Latina. Conflictos socioambientales, giro ecoterritorial y nuevas dependencias. Guadalajara: CALAS, 2019.

TADDEI, R. O lugar do saber local (sobre ambiente e desastres). Riscos de 
Desastres Relacionados à Água, p. 311-323, 2015.

TEMPER, L. Environmentalism of the dispossessed: mapping ecologies of resistance. p. 1-278, 2014.

TEMPER, L.; BENE, D. DEL; MARTINEZ-ALIER, J. Mapping the frontiers and frontlines of global environmental justice: the EJAtlas. Journal of Political Ecology, v. 22, n. 266642, p. 255-278, 2015.

ZUKERFELD, M. Tipologías sobre el conocimiento: una revisión crítica y una propuesta materialista. Revista CTS, v. 13, n. 39, p. 11-31, 2018. 


\title{
Resumen:
}

Este trabajo contribuye a la discusión sobre las potencialidades que ofrecen los conflictos socioambientales para transformar las relaciones sociedad-naturaleza. Partimos de la revisión de tres modos de producción de conocimiento (científico, activista y local/comunitario) para discutir la forma en que distintos actores y sus redes se posicionan en los conflictos. Argumento que los conflictos socioambientales permiten la emergencia de redes con estos modos de producción, que, en la dinámica del conflicto, entran en disputa, colaboran y se permean mutuamente, y que en ese proceso posibilitan no sólo la producción de nuevo conocimiento sino también la formación de nuevas categorías sociales con efectos materiales y simbólicos en la gestión de los territoritos y el medio ambiente.

Palabras-clave: Conocimiento local; conocimiento activista; movimientos sociales; conflictos socioambientales.

\begin{abstract}
:
This work contributes to the discussion on the potential offered by socio-environmental conflicts to transform societynature relationships. We start from the review of three modes of knowledge production (scientific, activist and local / community) to discuss the way in which different actors and their networks position themselves in conflicts. I argue that socioenvironmental conflicts allow the emergence of networks with these modes of production, which, in the dynamics of conflict, come into dispute, collaborate and mutually permeate each other, and in this process they enable not only the production of new knowledge but also the formation of new social categories with material and symbolic effects on the management of the territories and the environment.
\end{abstract}

Keywords: Local knowledge; activist knowledge; social movements; socioenvironmental conflicts. 
Recebido para publicação em 10/12/2019.

Aceito em 12/05/2020. 